\title{
The Academic Library and Its Environment*
}

The organizational environment of the library deserves greater attention by librarians and library administrators concerned with internal changes taking place within their organizations. Few systematic approaches to the impact of the environment upon the functioning of the individual library have been offered. This paper examines four approaches to assessing library/environmental impacts and identifies those areas for which an analytical model could be developed and applied by librarians and administrators.

$\mathrm{T}$ IIE PRACTICAL ART OF LIBRARY ORGAof its corresponding theory. The literature of librarianship reflects a preoccupation with the search for the one best way to organize the library, whereas practice encompasses a variety of organizational and managerial styles and configurations. Librarians know that an organizational structure suitable for a library of a liberal arts college in a rural setting probably is inappropriate for the library of a major urban college. They know that the management style and structure of the local college library differs from that of the local public library, although both libraries are in the same town. The thoughtful library manager recognizes individual differences in each library and structures his library accordingly.

Although many library schools, associations, and much library literature consider library problems by the type of library in which those problems occur, there has been no exploration of the

Beverly P. Lynch is executive secretary of the Association of College and Research Libraries, $a$ division of the American $\mathrm{Li}$ brary Association. differences arising from the environmental settings of libraries. It has been assumed that libraries are affected by their varying environments and that factors external to the library influence its internal operations. Although it has been recognized that external factors vary according to whether the library is a college, a public, or a school library, little is known about the impact of the environment upon the library.

Some of the classics in librarianship describe the library in its environmental context, but the more recent investigations of the library as an organization focus on intraorganizational phenomena. ${ }^{1}$ Marchant studies the characteristics of the library's decision-making process and the impact of that process upon staff satisfaction. ${ }^{2}$ Spence correlates measures of library size with various dimensions of library structure. ${ }^{3}$ Lynch measures the variability in the work of library departments before making predictions as to variations in the library's structure. ${ }^{4}$ Each of these studies examines only internal characteristics of the library.

- A revision of a paper presented to the Midwest Academic Librarians Conference, Luther College, Decorah, Iowa, May 19, 1973. 
This preoccupation with internal factors has led to the relative neglect of interorganizational relationships within librarianship. Libraries "are embedded in an environment of other organizations as well as in a complex of norms, values, and collectivities of the society at large." ${ }^{15}$ Librarians do recognize that the library is dependent to some degree upon its environment. Environmental factors within the university and the society at large have been identified as having an influence upon the library's structure $^{6}$

In the provocative article "The Changing Role of Directors of University Libraries," Arthur McAnally and Robert Downs describe characteristics of the university and society at large that affect the university library. ${ }^{7}$ They suggest that the recent turnover in university library directors occurred in response to the changing environment in which the university library is embedded: the library could not cope with the enormous expansion that took place within the university during the 1960s; the role of the library was reduced and its power diminished as the management patterns within the university changed; the expansion and fragmentation of knowledge influenced university curricula and design, and these patterns directly influenced the university library in terms of staffing patterns, responsibilities, decision making, and so forth.

The library can be viewed as an open system, affected by contingencies placed upon it by its environment. An open system is one in which some kind of exchange takes place between the system and its environment. The general perspective of the open system is that the organization obtains its resources and energy from its environment, transforms these resources into products, and exports the finished products or services back into the environment. ${ }^{8}$ With the open system, the organization is capable of bringing in resources to modify its own internal workflows, structures, and procedures.

If the library is studied as a system interacting with its environment and bringing resources (human, financial, and material) into the library, the dynamic aspects of the library's internal organization, design, and structure can be better understood. Because the environment can influence internal workflows, structures, and procedures, a study of the library and its environment can help identify changing aspects of library organization and varying organizational patterns as well as lead to development of predictive models for library organization.

\section{APPROACHES TO THE LIBRARY'S ENVIRONMENT}

Several approaches can be used to examine the library's environment. The following four areas are covered in this study:

(1) The nature of the environment itself.

(2) The relationships among the libraries within a set of organizations.

(3) The characteristics of the exchanges that take place among libraries.

(4) The impact that the environment has upon the library's internal structures and operations.

\section{The Nature OF THE ENVIRONMENT ITSELF}

A consideration of the nature of the environment itself is a contextual approach that describes the organizational effects produced by larger social processes surrounding the organization. Although the Public Library Inquiry and the more recent study conducted by Allie Beth Martin explore certain societallibrary relationships, and although several societal trends that affect the university library directly or indirectly have been identified, few library studies have 
explored the channels and types of influence exerted by the external environment upon interorganizational relations. ${ }^{9}$

There is no systematic, empirical evidence to confirm or deny the hypothesis that organizational change is increasingly externally induced. ${ }^{10}$ Librarians generally assume that organizational change in the library is internally generated. It is frequently said that if the managerial style of the library director would change, or if the staff had broader participation in the decision making, the library's performance would change. Environmental factors leading to less participation in decision making have not been considered, nor have factors that could reduce the decision-making autonomy of the library itself been identified.

A second hypothesis derives from the contextual nature of the organizational environment: "the organization's ability to adapt is a function of its ability to learn and to perform according to changing environmental contingencies."11 Most library literature calling for library application of computer technology or acquisition of current audiovisual materials supports the notion that the library must adapt or it will be replaced by different organizations.

It may be impossible to determine whether organizational change is internally or externally generated. An internal change may have external antecedents, and external events may have been initiated by internal sources. The point is that organizational change is influenced not only by internal factors. Librarians should be sensitive to these relationships.

\section{RELATIONSHiPS among Organizations Within a Set of Organizations}

Another approach to the study of libraries and their environments is to examine the interactions of organizations within a network of organizations. This approach uses one organization as a referent and analyzes that organization's relationships with elements in its organizational set. ${ }^{12}$

There are several aspects of the organizational set that can be used in the analysis of the interactions.

1. Those organizations in the set upon which the focal organization depends can be identified and their interactions characterized. The environment of any organization consists of a set of input organizations and a set of output organizations. The input organizations are those upon which the organization depends for its resources. In the library environment, input organizations would include such organizations as publishers, whose materials are inputs into the library's resources; library schools, whose students are inputs into the library's staff; and state libraries, whose funds may partially support the library. The output organizations are those for whom the organization produces a product or service. Within the library's environment output organizations would include other libraries, industrial firms, and other organizations. (As this analysis is an organizational one, the individual client is excluded.)

2. The reliance on input from various organizational resources can be assessed. An organization may depend upon few or many input sources. Whether the concentration of library input resources is high or low probably affects the structure and functioning of the library. Use of a single jobber, hiring students from the same library school, receiving monies from relatively few sources will have some impact upon the library.

3. Certain organizations within the same network are used by the focal organization for reference purposes. In addition to input and output sets, the library environment also includes a set of comparative reference organizations. 
These organizations are used by the library as a standard of comparison in evaluating its own performance. A set of normative reference organizations is also included in the library environment in order to incorporate the values and goals of this set into the focal organization.

Comparative reference groups and normative reference groups of most academic libraries can be specifically identified. For example, the comparative reference group of the library of the University of Wisconsin probably contains the other Big Ten university libraries. Its normative reference group probably includes the Social Science Data and Program Library Service of the University of Wisconsin, which houses the collection of machine-readable data files in the social sciences, and the Bureau of Audio-Visual Instruction, which services all films used in the university.

4. A fourth dimension of the organization set is its size. Although the size of the organization set is to be distinguished from the size of the focal organization, it is likely that the two are correlated; the larger the library, the larger the set of organizations with which it interacts. Although the size of the library does influence many internal characteristics, little attention has been paid to the size of the organization set interacting with the library. It is likely that the library's internal structure and processes are significantly influenced by the number of organizations with which the library interacts.

An analysis of the organization sets for various types of libraries may provide new insights into understanding variations in internal structures and patterns of decision making. Such analyses could lead to new categories of library problems and to an identification of unrecognized organization sets. By comparing organization sets with the library as a focal point with organization sets of economic, political, educational, or oth- er organizations, the structural arrangements for other types of organizations might be found inappropriate for academic libraries.

\section{Characteristics of Exchanges among ORganIzations}

Organizational exchange is defined "as any voluntary activity between two organizations which has consequences, actual or anticipated, for the realization of the [organization's] respective goals or objectives."13 Analysis of organizational exchange considers the content of the exchange itself and the organizational forces acting in the exchange. The analysis might examine the degree to which the exchange is formalized or given official sanction by the participating organization; the extent to which a coordinating mechanism has been established to operate the exchange; the degree of intensity or involvement demanded of the interacting organizations (the intensity can be measured by the size of the invested resources-staff activity, money, equipment, services-and by the frequency of interaction); and the extent of reciprocity, a critical dimension in the assessment of the relationships among autonomous organizations.

No doubt most librarians occasionally have asked a friend in another library to copy an article, answer a question, or help a patron. These activities can be described as informal exchanges between libraries. The librarian, as an agent of his library, in combination with others in his library doing the same thing, develops a system of informal exchange. This activity is quite different from a formal exchange arrangement sanctioned by the library to provide interlibrary loan, reference service, and other services. The new system of interlibrary loan in Wisconsin, WILS (Wisconsin Interlibrary Loan System), provides a coordinating mechanism different from the loan system previously op- 
erating in Wisconsin. Although there is no empirical evidence to describe the influence of the WILS system upon the individual libraries subscribing to it, many librarians working in those libraries are able to compare the two systems and identify differences in the characteristics of the exchange and in organizational patterns required to operate the exchange.

Organizations desiring to maintain autonomy might understandably show reluctance for exchanges where sacrifices exceed rewards. If library A enters into an exchange relationship with library B, A may assume that B will make demands on it. One of the norms of reciprocity implies that the exchange should be mutually beneficial and roughly equivalent. ${ }^{14}$ The voluntary system of interlibrary loan, an example of a library exchange, was developed so that libraries would share resources in order to achieve the common goal of service to readers. If reciprocity is to occur, the needs of both participating libraries must be fulfilled by the exchange. In most cases of interlibrary loan, however, the loans are beneficial only to the receiving library; the general professional goal of service, which previously sustained the voluntary interlibrary loan system, now appears to be inadequate.

Two additional factors inhibit the sharing of library resources: money has not been widely used to facilitate the flow of resources, and each autonomous library is accountable to its own major source of legitimacy (which is usually also its source of direct financial support) and is evaluated in terms of specific kinds of services rendered to selected users. As more money is acquired for circulation and as library autonomy decreases, library cooperation may increase.

Analysis of exchange in terms of these organizational characteristics should lead to the development of models for library exchange, which could be used to identify constraints that may be imposed upon certain types of library exchange.

\section{The IMPACT OF THE ENVIRONMENT UPON INTRAORGANIZATIONAL Properties}

The impact of the environment upon internal organizational design may provide the most immediate concern to librarians interested in the influence environmental factors might have upon library functions.

It has been suggested that complex, heterogeneous, and unstable environments impose more constraints and contingencies upon the organization and create greater decision-making uncertainty than environments that are simple, homogeneous, and stable. ${ }^{15}$ In a study of industrial firms, those departments with more uncertain environments relied less on formal rules and procedures, had fewer reviews of job performance, and were generally less formal than those departments in organizations with more certain environments. ${ }^{16}$ In a study of health and welfare agencies, those organizations that had more formal exchanges with other organizations reported more decentralized decision-making structures, were more innovative, and provided more formal mechanisms of communication. ${ }^{17}$

Not much is known about the impact of the environment upon the library's internal structure. When the influence of the environment is studied in a systematic manner, the many complexities of the library as an organization will be better understood.

\section{Organizational Boundaries and} THE ROLE OF THE BOUNDARY SPANNER

The study of the library in its environmental context is not an easy task. Before any investigation is undertaken of library-environment relationships, 
the boundaries of the library must be identified. Organizational boundaries do vary. Whereas one library may include a catalog department, another may use cataloging data provided by an outside processing center. One library may operate its own bindery, most will not.

An organization tends to expand its boundaries in order to reduce or eliminate major constraints and contingencies imposed upon it. For example, the single, statewide library network strives to include all libraries within its boundaries. If the state's major university library were not included, the network would be unable to control the cooperation of that library. A constraint would be placed upon the voluntary network system because the university library could reduce or remove its participation at any time. Such a constraint is eliminated by including the university library formally within the boundaries of the network.

The open-system approach to organizational studies assumes that the elements composing the organization can be further distinguished as to those elements within the organization and those elements outside the organization. Such a separation, however, is sometimes difficult and problematic. Some elements are engaged in transactions between the organization and its environment and hence are in both systems. Within the academic library, for example, the faculty library committee may be inside or outside the boundaries of the library. The committee members form a part of another system, the faculty-a major component of the academic library's environment.

In the context of these two systems, library and faculty, the faculty library committee serves as an interacting link. An analysis of the interaction provided by the faculty library committee or other such "boundary-spanning" units can indicate the amount of information flowing across the library's bound- aries. Furthermore, the amount of interaction taking place between the systems may have great impact upon the library and the rate of change occurring within it. ${ }^{18}$

The importance of organizational roles or job functions that span the boundaries of the library is relatively neglected by the subject literature. Boundary-spanning roles are defined "as those roles which link the focal organization with other organizations or social systems and are directly relevant for the goal attainment of the focal organization."19 The qualification of goal attainment is crucial, for without it most people working in the library could be defined as boundary spanners. Because the library's boundary-spanning roles are limited to those between the library and the elements in its task environment, it becomes necessary to define the boundary itself before the boundary spanners are identified and characterized. ${ }^{20}$

\section{Summary}

Librarians know that the organizational environment restricts what the library can do and influences individual characteristics of libraries. Little systematic investigation has been undertaken of library environments and the impact of those environments upon the individual library.

Four approaches to the study of library environments were outlined in this paper: identification of external environmental factors that may lead to some internal change within the library; measurement of environmental impact upon internal structural arrangements in libraries; investigation of relationships that exist between the library and other organizations with which it must deal; and analysis of the characteristics of exchanges that occur between the library and other organizations. Organizational boundaries and the role of the "boundary spanner" are two other important areas of study. 
Such investigations will broaden our understanding of constraints upon the library and will enable us to classify library environments and to develop an- alytical models that will provide the bases for assessing library/environmental relationships.

\section{REFERENCES}

1. Carleton B. Joeckel, The Government of the American Public Library (Chicago: Univ. of Chicago Pr., 1937).

2. Maurice P. Marchant, "The Effects of the Decision Making Process and Related Organizational Factors on Alternative Measures of Performance in University Libraries" (unpublished Ph.D. dissertation, Univ. of Michigan, 1970).

3. Paul Herbert Spence, "A Comparative Study of University Library Organizational Structure" (unpublished Ph.D. dissertation, Univ. of Illinois, 1969).

4. Beverly P. Lynch, "Library Technology; a Comparison of the Work Functional Departments in Academic Libraries" (unpublished Ph.D. dissertation, Univ. of Wisconsin, Madison, 1972).

5. William M. Evan, "The Organization-Set: Toward a Theory of Interorganizational Relations," in James D. Thompson, ed., Approaches to Organizational Design (Pittsburgh: Univ. of Pittsburgh Pr., 1966), p.175-91.

6. Edward G. Holley, "Organization and Administration of Urban University Libraries," CRL 33:175-89 (May 1972).

7. Arthur M. McAnally and Robert B. Downs, "The Changing Role of Directors of University Libraries," CRL 34:103-25 (March 1973).

8. Daniel Katz and Robert L. Kahn, The Social Psychology of Organizations (New York: Wiley, 1966).

9. Robert D. Leigh, The Public Library in the United States (New York: Columbia Univ. Pr., 1950); Allie Beth Martin, ed., A Strategy for Public Library Change (Chicago: American Library Association, 1972).

10. Shirley Terreberry, "The Evolution of Or- ganizational Environments," Administrative Science Quarterly 12:590-613 (March 1968).

11. Ibid.

12. Evan, "Organization-Set."

13. Sol Levine and Paul E. White, "Exchange as a Conceptual Framework for the Study of Interorganizational Relationships," Administrative Science Quarterly 5:583-601 (March 1961).

14. Anant R. Negandhi, ed., Organization Theory in an Interorganizational Perspective (Kent: Kent State University, Comparative Administration Research Institute of the Center for Business and Economic Research, 1971).

15. James D. Thompson, Organization in Action (New York: McGraw-Hill, 1967); Paul R. Lawrence and Jay W. Lorsch, Organization and Environment (Boston: Harvard University, 1967).

16. Lawrence and Lorsch, Organization and Environment.

17. Michael Aiken and Jerald Hage, "Organizational Interdependence and Inter-organizational Structure," American Sociological Review 33:912-30 (Dec. 1968).

18. Warren B. Brown, "Systems, Boundaries, and Information Flow," Academy of Management Journal 9:318-27 (Dec. 1966).

19. Michael Aiken and Jerald Hage, "Organizational Permeability, Boundary Spanners, and Organizational Structure," mimeographed (Madison: University of Wisconsin, Department of Sociology).

20. William R. Dill, "Environment as an Influence on Managerial Autonomy," Administrative Science Quarterly 2:409-43 (March 1958). 